\title{
Rancang Bangun Mesin CNC Laser Cutting Untuk Pembelajaran Mahasiswa Jurusan Teknik Mesin
}

\author{
Abdul Salam ${ }^{* *}$, Syaharuddin Rasyid ${ }^{2}{\text { Fadly } \text { Ta'bi }^{3} \text {, Resa Fahrisal }}^{4}$, Muhajirin ${ }^{5}$ \\ 1,2,3,4,5 Jurusan Teknik Mesin, Politeknik Negeri Ujung Pandang, Makassar 90245, Indonesia \\ *abdsalam@poliupg.ac.id
}

\begin{abstract}
This study aims to streamline time and improve the accuracy of the manufacture of engraved contour products on workpieces such as soft metals, acrylics, and wood. The Mini CNC Laser Cutting machine this research output will be used as one of the practicum jobs for the NC Basic Programming Practice course. The design method used is experimental applied research in the form of design and drawing for the laboratory with its dimensions of $45 x 45 \mathrm{~cm}$. Furthermore, the calculation and selection of materials, the manufacture of machine components and the use of Arduino uno software as a basic programming language to convert motion to tools. Testing the performance of the engine in the two-axis movement mode, namely, manual mode, $M D I$, and automatic second axis $X$ and $Y$ using the NC program. The results obtained show the accuracy and precision of the $X$ and $Y$ axis trajectories according to the permissible tolerance values, namely $0.01 \mathrm{~mm}, 0.01 \mathrm{~mm}$ and $0.05 \mathrm{~mm}$, respectively. The suitability of the program made and the machining results on the contour of the workpiece engraving do not show significant deviations, respectively $0.1 \mathrm{~mm}$ for the $X$ and $Y$ axis.
\end{abstract}

Keywords: Mini CNC Laser Cutting Machine, X, Y, Z Coordinate, Arduino uno

\begin{abstract}
Abstrak: Penelitian ini bertujuan untuk mengefisienkan waktu dan meningkatkan keakuratan pembuatan produk kontur ukiran pada benda kerja seperti logam lunak, akrilik, dan kayu. Mesin Pemotong Laser Mini CNC keluaran penelitian ini nantinya digunakan sebagai salah satu tugas praktikum mata kuliah Praktik Pemrograman Dasar NC. Metode perancangan yang digunakan adalah penelitian terapan eksperimental berupa rancangan dan gambar untuk laboratorium dengan ukuran $45 \times 45 \mathrm{~cm}$. Selanjutnya dilakukan perhitungan dan pemilihan bahan, pembuatan komponen mesin dan penggunaan software Arduino uno sebagai bahasa pemrograman dasar untuk mengubah gerak menjadi alat. Pengujian performa mesin pada mode pergerakan dua sumbu yaitu mode manual, MDI, dan otomatis sumbu kedua $\mathrm{X}$ dan $\mathrm{Y}$ menggunakan program NC. Hasil yang diperoleh menunjukkan keakuratan dan ketepatan lintasan sumbu X dan Y sesuai nilai toleransi yang diijinkan, yaitu masing-masing $0,01 \mathrm{~mm}, 0,01 \mathrm{~mm}$ dan $0,05 \mathrm{~mm}$. Kesesuaian program yang dibuat dan hasil pemesinan pada kontur ukiran benda kerja tidak menunjukkan penyimpangan yang berarti, masing-masing 0,1 mm untuk sumbu $\mathrm{X}$ dan $\mathrm{Y}$.
\end{abstract}

Kata kunci: Mini CNC Laser Cutting Mesin; X,Y, Z Koordinat, Arduino uno

\section{PENDAHULUAN}

Penggunaan dan kebutuhan mesin CNC Training Unit 3 Axis di Indonesia saat ini mengalami peningkatan khususnya untuk praktikum di sekolah-sekolah kejuruan dan perguruan tinggi teknik di Indonesia (Pramono, 2015). Meskipun kebutuhan mesin CNC meningkat, namun harga mesin CNC Training Unit di pasaran masih cukup tinggi yakni berkisar 100-500 jutaan dan hanya memiliki luas area kerja yang kecil $(30 \mathrm{~cm}$ x $30 \mathrm{~cm})$. Kisaran harga tersebut tentu saja cukup mahal sehingga tidak dapat dijangkau oleh sekolah-sekolah kejuruan dan lingkungan kampus. Oleh karena itu, perlu adanya solusi untuk mengatasi hal tersebut diantaranya dengan melakukan pembuatan mesin $\mathrm{CNC}$ yang lebih ekonomis dengan fungsi dan ketelitian yang sama.

Mesin CNC Laser Cutting merupakan penggabungan teknologi CNC (Computer Numerical Control) dan laser, cutter yang mampu memotong bentuk-bentuk lembaran kayu atau material lunak lainnya yang memiliki bentuk rumit dan membutuhkan ketelitian dalam pemakanan. Gabungan ini membentuk sebuah mesin pemotong yang dikontrol oleh komputer dengan menggunakan mesin router untuk memotong berbagai bahan seperti kayu, komposit, aluminium, baja lunak, plastik, kaca akrilik, dan busa dengan mengadopsi teknologi CNC. Pergerakan pemotongan dan lintasan cutter untuk sumbu $\mathrm{X}, \mathrm{Y}$, dan $\mathrm{Z}$ berasal dari program komputer berdasarkan gambar ataupun desain kontur lintasan yang telah dibuat.

Pembelajaran mata kuliah teori dan praktik Pemrograman $\mathrm{CNC}$ merupakan mata kuliah kompetensi di Jurusan Teknik Mesin. Oleh karena itu, mahasiswa harus menguasai dan terampil 
menggunakan mesin $\mathrm{CNC}$ sesuai dengan kebutuhan industri dan mengadopsi dengan cepat perkembangan penggunaan mesin-mesin $\mathrm{CNC}$ secara luas, termasuk mesin-mesin perkakas berbasis pengontrolan CNC seperti halnya mesin CNC Router, Mesin CNC Laser Cutting dan lainlain.

Mesin-mesin CNC yang ada di Laboratorium CNC Jurusan Teknik Mesin Politeknik Negeri Ujung Pandang sudah memasuki masa pakai yang lama (sekitar 25 tahun), sebagian besar sudah tidak berfungsi dan tidak optimal, memerlukan peremajaan atau penggantian. Keterbatasan dana anggaran mengharuskan adanya kreativitas dan usaha serius untuk "meretrovit" mesin-mesin $\mathrm{CNC}$ yang ada termasuk merancangbangun mesin CNC Router Mini dan Mesin CNC Laser Cutting Mini agar kompetensi mahasiswa tetap dapat dicapai sesuai tuntutan kurikulum KKNI. Keberadaan mesin hasil penelitian ini sangat membantu mahasiswa Jurusan Teknik Mesin dalam meningkatkan keterampilan mereka, khususnya pada praktikum pemrograman mesin CNC di Prodi D-4 Teknik Manufaktur, D-4 Teknik Mekatronika, dan Prodi D-3 Teknik Mesin.

Mesin CNC Laser Cutting saat ini semakin luas penggunaannya, tidak terbatas pada industri manufaktur saja, tetapi juga untuk industri kerajinan pada usaha-usah kecil menengah seperti usaha mebel dan interior rumah. Sementara untuk merancangbangun mesin CNC Laser Cutting untuk skala Lab. dan industri kecil saat ini relatif sudah lebih mudah dilakukan mengingat perkembangan teknologi dan kemudahan mendapatkan komponen-komponen standar dan komponen pendukung serta software pendukung yang dapat dibeli dengan lebih murah (free version) karena kapasitasnya yang dibatasi untuk penggunaan program 500 baris, sedangkan untuk software commercial version yang digunakan untuk industri penggunaan program bisa sampai 10.000.000 baris program. Adanya pengembangan inovasi dibidang otomasi khususnya mesin $\mathrm{CNC}$ di dunia industri memberikan dampak yang sangat baik. Ini disebabkan karena peralatan pemesinan konvensional yang hanya dapat dilakukan secara manual, dapat dilakukan secara otomatis dengan adanya mesin $\mathrm{CNC}$.

Pada umumnya dalam pengerjaan pemesinan, dibutuhkan pengerjaan yang lebih cepat, kualitas yang lebih baik namun dengan biaya pengerjaan yang lebih rendah. Hal ini menjadi daya tarik para konsumen industri untuk menggunakan mesin CNC dibandingkan dengan menggunakan mesin konvensional. Dengan adanya kelebihan dalam segi produktivitas akan menjadi daya saing tersendiri bagi industri yang menggunakan mesin CNC itu sendiri (Amala, 2014). Perkembangan dari pemesinan secara manual menjadi pemesinan yang menggunakan sistem CNC (Computer Numerical Control) menjadi sebuah kelebihan dalam meningkatkan ketepatan dan pengaturan kecepatan sesuai yang diinginkan. Sebuah mesin dengan proses pemotongan dimaksudkan sebagai sebuah mesin yang melakukan pengurangan dimensi sampai menjadi produk yang diinginkan. Sebagai contoh mesin bubut, mesin gurdi, dan dan mesin sekrap. Mesin CNC sendiri dapat diartikan sebagai suatu mesin perkakas yang pengoperasiannya dikendalikan melalui program yang diakses dengan komputer (Salam, 2014).

Penelitian produk terapan unggulan perguruan tinggi ini sangat penting untuk dilaksanakan karena penelitian ini menghasilkan luaran produk inovasi dan pengembangan ipteks, yaitu mesin CNC Laser Cutting Mini yang dapat dimanfaatkan oleh mahasiswa untuk praktikum pemrograman permesinan CNC di Lab. CNC dan juga dapat dimanfaatkan oleh masyarakat industri untuk meningkatkan produktivitas usaha kerajinan mebel atau interior rumah dan lain sebagainya.

Mesin CNC Laser Cutting adalah mesin yang dilengkapi dengan DSP (digital signal processing) dalam memotong atau mengukir bahan. Pengoperasian mesin dapat dilakukan secara otomatis dengan komputer dan manual dengan layar monitor portable. Mesin ini memiliki 3 macam fungsi, yaitu untuk memotong (cutting), menggrafir (engrafing), dan memberi tanda/marka (marking). Menurut Jundurrahman (2018), walaupun harga controller mach3 berbanding cukup jauh dengan kinerja PLC pada mesin-mesin pabrikan terkenal, namun keakuratan dan ketepatan mesin CNC Laser Cutting Mini 2 axis ini dapat bersaing sehingga dapat menunjang proses praktikum pemrograman Mesin $\mathrm{CNC}$ yang ada di sekolah-sekolah kejuruan dan di perguruan tinggi teknik. 
3 Abdul Salam, Syaharuddin Rasyid, Fadly Ta'bi, Resa Fahrisal, Muhajirin. Rancang Bangun Mesin Cnc Laser Cutting Untuk Pembelajaran Mahasiswa Jurusan Teknik Mesin

\section{METODOLOGI PENELITIAN}

Penelitian ini dilaksanakan selama tiga bulan, dari bulan Mei 2019 sampai bulan Juli 2019. Adapun tempat pengerjaan sebagian besar dikerjakan di bengkel produksi CNC dan sebagian lagi dikerjakan di Bengkel Mekanik Politeknik Negeri Ujung Pandang.

Bahan-bahan yang digunakan antara lain besi profil L, profil $\mathrm{U}$, besi plat, besi balok alumunium, timing belt, braket motor, baut dan mur, elektroda las, puli dan sabuk pelat gerigi, bantalan, driver motor, power supply, motor stepper, module laser, software arduino uno, dan kabel control switch, serta cat dan kelengkapannya.Sedangkan peralatan yang digunakan adalah mesin bubut, mesin potong, mesin gerinda, mesin bor, mesin las, alat-alat ukur, penyiku, dan kunci pas.

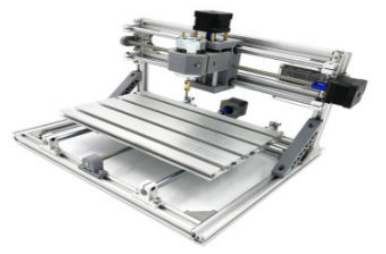

Gambar 1. Desain konstruksi mesin CNC Laser Cutting

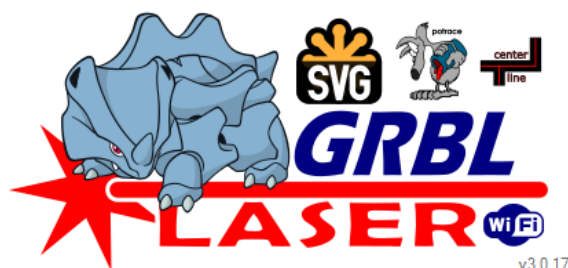

Gambar 2. Tampilan muka Software Lasergrbl

\section{Langkah Kerja Penelitian}

Langkah kerja penelitian rancang bangun terbagi atas beberapa tahapan, secara garis besar pada umumnya meliputi Perancangan (Design \& Drawing), Pembuatan komponen (manufacturing process), Proses Assembly, dan Pengujian Fungsi Mesin (Sonawan, 2013). Langkah kerja tersebut diuraikan sebagai berikut:

1. Perancangan (Design \& Drawing)

Dalam pembuatan produk digunakan dasar gambar desain mesin, dimana perancangan menggunakan software Autodesk Inventor.

2. Proses Manufaktur (Manufacturing Process)

Komponen yang dikerjakan adalah: Meja mesin Laser Cutting, Braket module laser, dan Braket motor axis. Braket motor axis adalah bagian dari komponen mekanik mesin CNC Laser Cutting yang berfungsi sebagai dudukan motor axis. Komponen ini dibuat dari aluminium balok lalu di proses permesinan menggunakan mesin milling sesuai dengan rancangan.

3. Prosess Assembly

Pada tahap ini dilakukan perakitan komponen yang telah dibuat termasuk penambahan komponen elektrik membentuk sebuah mesin yang komplit.

4. Pengujian Fungsi Mesin

Pengujian fungsi dilakukan untuk memeriksa apakah semua tombol dan switch pada mesin telah berfungsi sesuai dengan fungsinya dan pengujian ukuran mesin dilakukan untuk memeriksa apakah ukuran dan gerakan aktual pada mesin telah sesuai dengan apa yang telah diinput pada program. Hasil kalibrasi pada mesin CNC laser cutting 2 axis dilakukan dengan alat bantu dial indicator dan block gauge, untuk mengetahui sumber kesalahan apa saja yang dapat dideteksi dengan cara kalibrasi sumbu X dan Y mesin CNC laser cutting(Zaynawi, 2018). 
Apabila mesin belum berfungsi dengan baik pada proses pengujian fungsi mesin dan ukuran maka akan dilakukan perbaikan atau pergantian komponen untuk kemudian dirakit kembali, selanjutnya dilakukan kembali pengujian sampai mesin dapat berfungsi dengan baik.

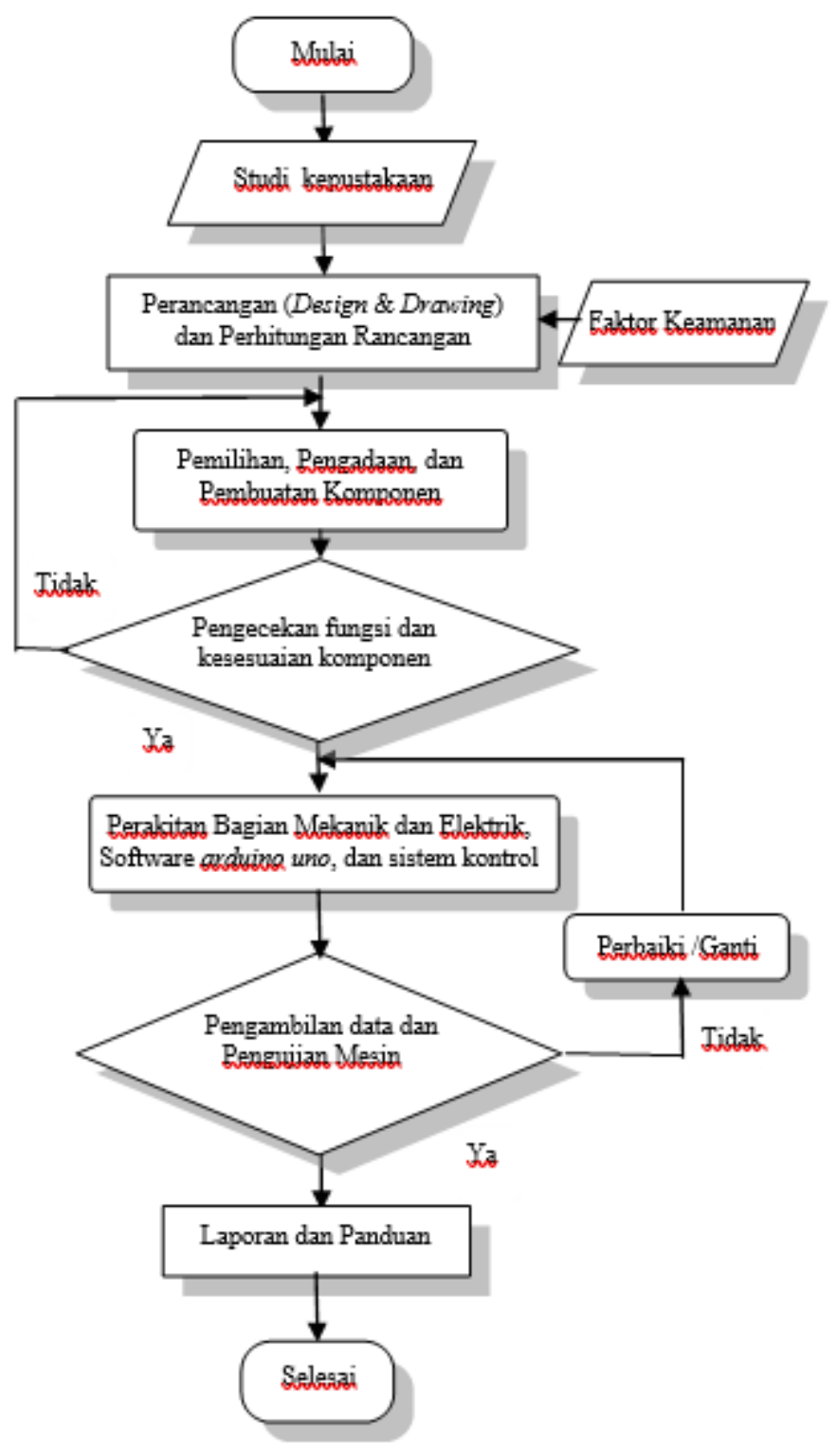

Gambar 3. Diagram Alir Rancang bangun Mesin

\section{HASIL DAN PEMBAHASAN}

\subsection{Perancangan Mesin CNC Laser Cutting}

Perancangan mesin CNC Laser Cutting yang paling utama adalah perencanaan daya motor yang diperlukan agar sesuai dengan kebutuhan. Menggunakan motor stepper 200 pulse/rotasi dengan kecepatan pulse masuk 1000 pulsa/detik, maka kecepatan putar motor: $n=60 \frac{\text { pps }}{N p}$, diperoleh $\mathrm{n}=300 \mathrm{rpm}$. Untuk menghitung daya yang bekerja pada motor, perlu di ketahui torsi yang bekerja pada motor. Berdasarkan perhitungan daya motor, berturut-turut diperoleh daya untuk sumbu Y, $\mathrm{PY}=\mathrm{T}$ x w $=0.0964 \times 31,4=3,028$ watt dan untuk sumbu X, PX $=0,258$ watt. Karena daya motor stepper yang digunakan 72 Watt, maka kebutuhan daya penggerak mesin aman. 
5 Abdul Salam, Syaharuddin Rasyid, Fadly Ta’bi, Resa Fahrisal, Muhajirin. Rancang Bangun Mesin Cnc Laser Cutting Untuk Pembelajaran Mahasiswa Jurusan Teknik Mesin

\subsection{Pengujian Ukuran dan Kalibrasi mesin}

- Kalibrasi dengan Software Lasergrbl

Software universal gcode sender memiliki pengaturan khusus untuk memastikan perintah jarak yang dimasukkan telah sesuai dengan jarak aktual pada mesin.
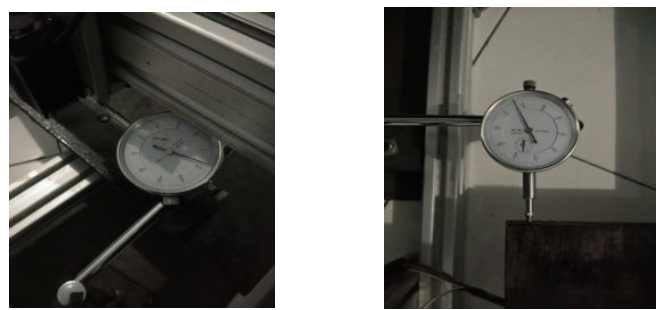

Gambar 4. Hasil pembacaan axis X dan Y proses kalibrasi

Tabel.1. Data Hasil kalibrasi dengan software Lasergrbl

\begin{tabular}{|c|l|c|c|}
\hline \multicolumn{2}{|c|}{ Axis } & $\begin{array}{c}\text { Pembacaan } \\
(\mathrm{mm})\end{array}$ & $\begin{array}{c}\text { Penyimpangan } \\
(\mathrm{mm})\end{array}$ \\
\hline \multirow{2}{*}{$\mathrm{X}$} & Sebelum dikalibrasi & 0.93 & -0.07 \\
\cline { 2 - 4 } & Setelah dikalibrasi & 1 & 0 \\
\hline \multirow{2}{*}{$\mathrm{Y}$} & Sebelum dikalibrasi & 1.65 & +0.65 \\
\cline { 2 - 4 } & Setelah dikalibrasi & 1 & 0 \\
\hline
\end{tabular}

Kalibrasi dilakukan dengan menggerakkan axis $\mathrm{X}$ dan $\mathrm{Y}$ sejauh $1 \mathrm{~mm}$. Penyimpangan pada pergerakan axis $X=0.10 \mathrm{~mm}$ dan $\mathrm{Y}=0.18 \mathrm{~mm}$. Setelah mesin CNC Laser Cutting dikalibrasi tidak terdapat penyimpangan pada axis atau penyimpangan sama dengan 0 .

\section{- Pengujian Pergerakan pada Mode MDI (Manual Data Input)}

Mode MDI dilakukan untuk mengerakkan axis dengan memasukkan program pada software Lasergrbl secara manual. Pengujian dengan mode MDI dilakukan sebanyak lima kali yaitu axis digerakkan sejauh $0.01 \mathrm{~mm}, 0.10 \mathrm{~mm}, 1.00 \mathrm{~mm}, 3.00 \mathrm{~mm}$, dan $5.00 \mathrm{~mm}$.

Tabel 2. Data hasil pengujian pergerakan axis pada mode MDI

\begin{tabular}{|c|c|c|c|c|c|c|}
\hline \multirow{2}{*}{\multicolumn{2}{c|}{ Axis }} & \multicolumn{5}{c|}{ Pengujian } \\
\cline { 3 - 7 } \multicolumn{2}{c|}{} & 1 & 2 & 3 & 4 & 5 \\
\hline \multirow{3}{*}{$\mathrm{X}$} & Input program & 0.01 & 0.10 & 1.00 & 3.00 & 5.00 \\
\cline { 2 - 7 } & Nilai pergerakan axis & 0.01 & 0.10 & 1.00 & 3.00 & 5.01 \\
\cline { 2 - 7 } & Penyimpangan & 0.00 & 0.00 & 0.00 & 0.00 & +0.01 \\
\hline \multirow{3}{*}{$\mathrm{Y}$} & Input program & 0.01 & 0.10 & 1.00 & 3.00 & 5.00 \\
\cline { 2 - 7 } & Nilai pergerakan axis & 0.01 & 0.00 & 1.01 & 3.00 & 5.00 \\
\cline { 2 - 7 } & Penyimpangan & 0.00 & 0.00 & +0.01 & 0.00 & 0.00 \\
\hline
\end{tabular}
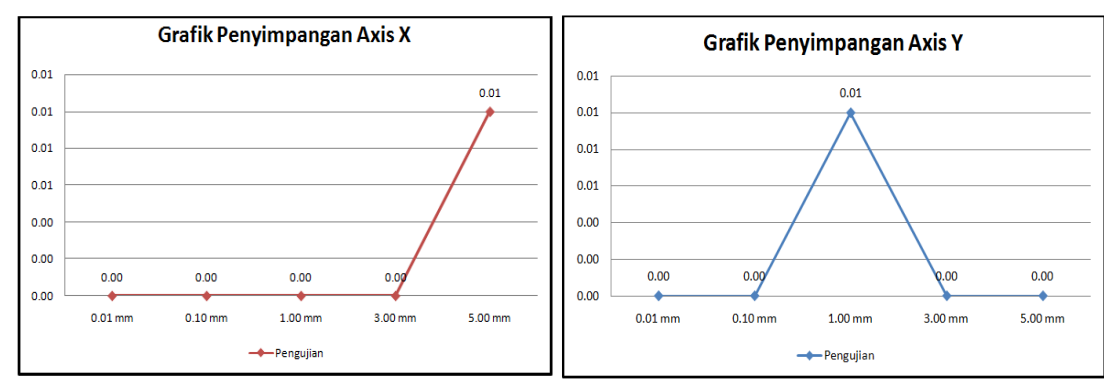

Gambar 5. Grafik penyimpangan axis $\mathrm{X}$ dan $\mathrm{Y}$ pada mode MDI 
Berdasarkan dari ketiga grafik di atas dapat diketahui bahwa penyimpangan terbesar pada axis $\mathrm{X}$ adalah $0.01 \mathrm{~mm}$ dan pada axis $\mathrm{Y}$ penyimpangan terbesar yaitu $0.01 \mathrm{~mm}$.

- Pengujian Pergerakan pada Mode Otomatis Dengan Program NC

Setelah dilakukan kalibrasi dan pengujian pergerakan serta ukuran dengan menggunakan Software Lasergrbl dan mode MDI maka selanjutnya dilakukan pengujian pergerakan pada mode otomatis dengan membuat program pada software Aspire dan menggunakan software Lasergrbl untuk mengeksekusi benda kerja. Adapun material benda kerja yang digunakan adalah plastik fiber dan tripleks, alat ukur yang digunakan dalam pengujian ini adalah jangka sorong.
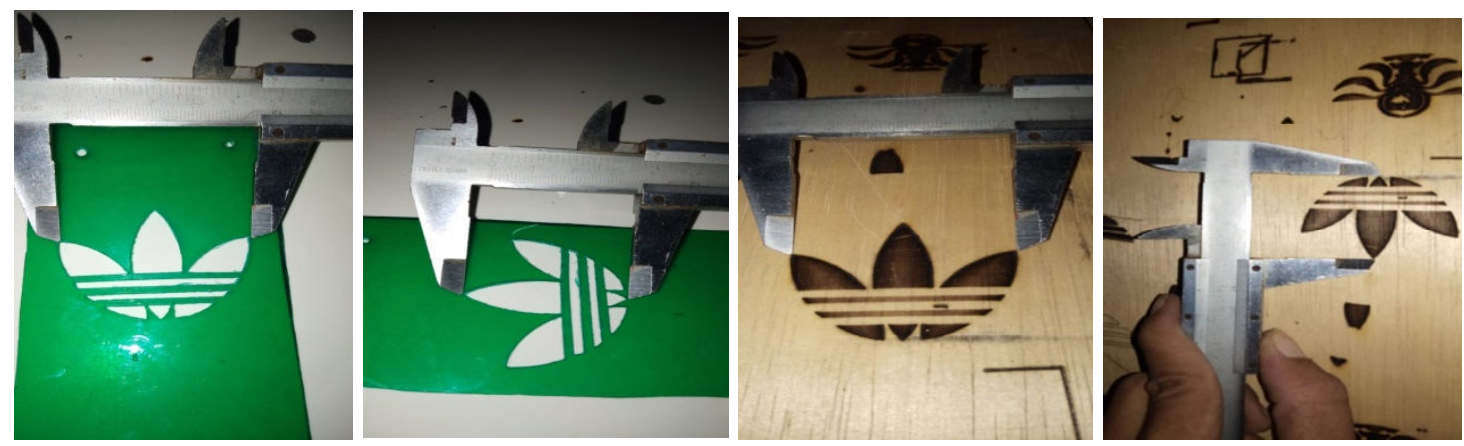

Gambar 6. Hasil Pengujian Benda Kerja hasil program Aspire

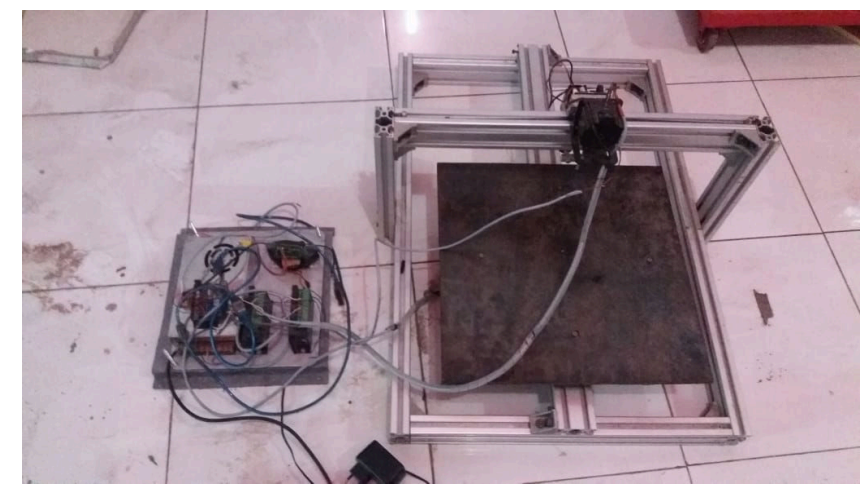

Gambar 7. Mesin CNC Laser Cutting

\section{KESIMPULAN}

\section{Kesimpulan}

Dari hasil dan pembahasan penelitian dapat disimpulkan :

1) Telah diperoleh Prototype mesin CNC Laser Cutting dengan dimensi mesin $900 \mathrm{~mm} \mathrm{x}$ $900 \mathrm{~mm} \times 950 \mathrm{~mm}$ dengan menggunakan jenis laser diode memiliki panjang gelombang $405 \mathrm{~nm}$ dan daya $2500 \mathrm{~mW}$ dengan ketelitian pemotongan $0,01 \mathrm{~mm}$.

2) Telah diperoleh hasil produk dari mesin CNC Laser Cutting pada proses cutting adalah hasil potong halus yang memiliki penyimpangan $0,12 \mathrm{~mm}$ dan pada proses engraving adalah hasil grafir yang agak hangus yang memiliki penyimpangan $0,17 \mathrm{~mm}$.

3) Biaya pembuatan mesin CNC Laser cutting yaitu Rp. 10,000,000. Biaya ini masih tergolong murah untuk digunakan sebagai praktikum dalam sekolah kejuruan ataupun perguruan tinggi dibandingkan harga mesin Laser Cutting di pasaran yang berkisar dengan harga mencapai Rp. 69,000,000,-- 
7 Abdul Salam, Syaharuddin Rasyid, Fadly Ta’bi, Resa Fahrisal, Muhajirin. Rancang Bangun Mesin Cnc Laser Cutting Untuk Pembelajaran Mahasiswa Jurusan Teknik Mesin

\section{Saran}

Berdasarkan hasil pengamatan penulis, eretan yang ada pada axis Y saat ini sudah tidak presisi. Dari hasil penelitian nilai penyimpangan terbesar terjadi pada axis y yang digerakkan pada mode manual yaitu sebesar $0.1 \mathrm{~mm}$ yang pada umumnya tingkat ketelitian mesin CNC yaitu $0.01 \mathrm{~mm}$. Sehingga perlu dilakukan pergantian komponen eretan pada axis Y.S

\section{DAFTAR PUSTAKA}

[1] Pramono, Gatot Eka dkk. Rancang Bangun CNC Mini Router 3 Axis untuk Keperluan Praktikum CAD/CAM. Tugas Akhir Program Studi Teknik Mesin. FT-UIK. Bogor: Universitas Ibnu Khaldun. 2015.

[2] Salam, Abdul. Pemrograman Dasar NC. Makassar: Deepublish. 2014.

[3] Amala, Mushafa, Susilo dan Adi Widyanto. Pengembangan Perangkat Lunak Sistem Operasi Mesin Milling CNC Trainer. Jurnal Teknik Mesin S-1 Vol.2 No. 3. 2014.

[4] Jundurrahman. Teknologi Tepat Guna mesin CNC Milling 3 Axis Berbasis Mach-3 Controller. Tugas Akhir. Program Studi Teknik Mekatronika. Makassar: Politeknik Negeri Ujung Pandang. 2018.

[5] Sonawan, Hery. Perancangan Elemen Mesin. Bandung: Alfabeta. 2013.

[6] Zaynawi, Bayu Wiro. K, Fipka Bisono. Proses Kalibrasi Sumbu X, Y, Dan Z Pada Mesin CNC Router Kayu 3 Axis Menggunakan Alat Bantu Dial Indicator dan Block Gauge. Jurnal PPNS. Program Studi Teknik Desain dan Manufaktur. Jurusan Teknik Permesinan Kapal. Surabaya: Politeknik Perkapalan Negeri Surabaya. 2018.

[7] Salam, Abdul. Jobsheet Praktik Produksi Pemrograman Numerical Control (PNC)-1. Makassar: Politeknik Negeri Ujung Pandang. 2015.

[8] Fernety, Art dan John Prentice. Using Mach3Mill or The Nurture, Care and Feeding of The Mach3 Controlled CNC Mill. ArtSoft Software Incorparted. 2013.

[9] Harrizal, Ikhlash Syukran, Syafri dan Prayitno. Rancang Bangun Sistem Kontrol Mesin CNC Milling 3 Axis Menggunakan Close Loop System. JOM FKTEKNIK. Vol. 4 (2). Pekanbaru: Universitas Riau. 2017.

[10] Toguan Samarya, Yenny. 2015. Aplikasi Laser CO2 Untuk Pemotongan (Cutting) Material Menggunakan Mesin CNC (Control Numeric Computer). Jurnal Fmipa Vol. 10 No. 1.

[11] Wijanarka, B Sentot. 2011. Modul Teknik Permesinan Frais. Yogyakarta: Universitas Negeri Yogyakarta.

[12] Suh, S.-H., Kang, S.-K., Chung, D.-H., \& Stroud, I. (2008). Theory and Design of CNC Systems. London: Springer. 